\title{
The Effects of Intrinsic and Extrinsic Rewards on Employee Attitudes; Mediating Role of Perceived Organizational Support
}

\author{
Ayesha Ajmal1, Mohsin Bashir ${ }^{*}$, Muhammad Abrar², Muhammad Mahroof Khan ${ }^{3}$, \\ Shahnawaz Saqib1 \\ ${ }^{1}$ Department of Business Administration, GC University, \\ Faisalabad, Pakistan \\ ${ }^{2}$ Department of Business Administration, National Textile University, \\ Faisalabad, Pakistan \\ ${ }^{3}$ Department of Economics, University of Management Science \& Information Technology, \\ Kotli, Pakistan \\ Email: ${ }^{\text {mohsinhust@gmail.com }}$
}

Received 4 June 2015; accepted 17 July 2015; published 21 July 2015

Copyright (C) 2015 by authors and Scientific Research Publishing Inc.

This work is licensed under the Creative Commons Attribution International License (CC BY). http://creativecommons.org/licenses/by/4.0/

(c) (i) Open Access

\section{Abstract}

The purpose of this study was to measure the effect of intrinsic and extrinsic rewards on employee attitudes, job satisfaction and organizational commitment as well as the mediating role of perceived organizational support. Data were collected from banking sector of Faisalabad, Pakistan. The main objective was to focus the employee's perception about the organizational support and employees' satisfaction and organizational commitment. The mediation effect of perception of organizational support was analyzed between the relationship of intrinsic \& extrinsic rewards and employee attitudes like organizational commitment and job satisfaction. The study revealed that employees felt positively about intrinsic and extrinsic rewards. Limitations and future directions had also been discussed.

\section{Keywords}

Rewards, Incentives, Organizational Perception, Organizational Commitment, Job Satisfaction, Employee Attitudes

\footnotetext{
${ }^{*}$ Corresponding author.

How to cite this paper: Ajmal, A., Bashir, M., Abrar, M., Khan, M.M. and Saqib, S. (2015) The Effects of Intrinsic and Extrinsic Rewards on Employee Attitudes; Mediating Role of Perceived Organizational Support. Journal of Service Science and Management, 8, 461-470. http://dx.doi.org/10.4236/jssm.2015.84047
} 


\section{Introduction}

This study explored knowledge about the importance of intrinsic and extrinsic rewards for the development of believe in employees or concept among employees about perceived organizational support (POS) to engage them to their work effectively and retain them satisfied with their work environment. Furthermore, the perceived organization support is taken as mediators which will also affect the job satisfaction level of employee's, gradually organizational commitment in employees and also change employees' attitude towards work positively.

Extrinsic rewards are support to the direct satisfaction of money needs and intrinsic rewards which are found helpful for the acknowledgment of employees and that recognition is a motivation point for the employees to the work engagement. Most of the literature proves that the encouragement and the appraisal or the reward system of the employees result in the higher employee retention rates, productivity and job satisfaction. The organizations whose employees have the perception that the organization treats them in sufficiently well manner will get the best effort from their employees towards the work. For instance, the well treated employees are more engaged with the work and much more committed to organization [1] and the organizations whose employees are treated like a machine will leave the organization or work less committed with the organization [2].

Employees' commitment for their job depends on perceived organization support which also affects employees' attitude towards work and their satisfaction level. So, the attitude of employees also affects the organization commitment and job satisfaction.

Employee attitude describes the actions of employees towards their objectives and goals. Employee attitude includes three major dimensions, which are following affective attitude and a cognitive and individual's attitude. The affective attitude includes the emotional factor, feeling of employees and values or norms. The cognitive attitude focuses on the employee's belief about the right and wrong concept. Lastly, the behavioral employee's attitude shows the intensions and decision making will and power [3].

Job satisfaction of employees is increased in different manners by the different tools. The main two factors that raise the employee job satisfaction level are intrinsic and extrinsic motivational factors in shape of rewards system. Job satisfaction refers to employees output against their remuneration and other supports from the organization. Job satisfaction reflects the influence of intrinsic and extrinsic rewards as a result of employee attitude and positive effective employee performance.

After understanding the definition of job satisfaction, in this study we focus on the other side of employee attitude. These studies aim at satisfying the employee to get the commitment and loyalty of employees. Huge amount of literature find the influences and the relationship of organizational commitment and employee attitude. Organizational commitment concept must be understood before going forward. The organizational commitment is defined by many researchers in many ways.

Organizational commitment is found when employees and organization goals and values have the same direction and employees then want to stay with organization and remain loyal to for their interest and organizations interest.

The perception of organizational support is used in this study as the mediating variable. Perception of employee about the support given by the organization for their wellbeing mediates the relationship between the employee's intrinsic and extrinsic rewards and employee job satisfaction and organizational commitment. Perception refers to the mindset of employees about the values given by organization in return of their hard work and extra effort for the benefit of organization. Perception of organization support among employees could be raised by many motivational factors. Main two motivational factors are intrinsic and extrinsic rewards, which influence the employee's thoughts at very great extent and make employees mind about organizational support. Exchange of support among employees and organization refers as the main base of organization support theory in employee mind, which affects the employee satisfaction level and loyalty towards the organization [4].

This study is conducted to check the intrinsic and extrinsic rewards relations and effects. Herzberg works lot on the rewards system. He explains that intrinsic and extrinsic rewards has the more effective influence on the employees effectiveness and motivational level or employees satisfaction and commitment level, when implemented in industrial institutions. Critically low performance of employees and organization is output of low motivation level in employees, which outputs could be low satisfaction level, higher turnover ratio and increase in absenteeism ratio of employees. Less satisfied employee's turnover ratio is increased due to boring environment or irrelevant routine work which results in employees work burnout or leaves the organization for better option.

Rewards system has much importance in modern era. In private and public sectors, rewards have the main 
role to keep employees motivated and attached with their work. The association and the relation between employee's perception, rewards and employee job satisfaction have the great influence on every organizational structure [5]. Comparing the weight or value of intrinsic and extrinsic rewards, researchers find out that both rewards have their own preferences depending on employees need. Some employees need intrinsic rewards (mostly higher management) and other employees prefer extrinsic rewards (mostly in lower level management). Higher level employees focus on recognition, acknowledgement, empowerment and other intrinsic rewards. These types of intrinsic and extrinsic rewards become the base of employee's perceived organizational support. Employee's perception about organization develops in positive manner and they feel that the organization values their contribution and returns the rewards for their hard working and efforts. Human resource is the most important source of any organization performance. When employees feel rewards are for their development and caring perspective by organization, they are found more satisfied and committed to their jobs [6].

\section{Review of Literature}

\subsection{Intrinsic Rewards and Extrinsic Rewards effects on Job Satisfaction}

Rewards system is designed by keeping in mind the organizational productivity direction affected by the rewards in positive and negative manners. The activities and outcomes of employee's contribution in organization influence the organizational performance. The relation of employees and organizational activities increased the employee skills and knowledge, commitment and organizational productivity [7].

Many studies provide evidences about the rewards system are important for employee's outcomes in productivity manner. But not specific rewards are mention for increase in productivity of organizational performance. We define rewards generally to include all types of rewards, both extrinsic and intrinsic. We cannot neglect one type of rewards to promote the other one. Both types of rewards have their importance according to the need and situation. Extrinsic rewards have the impact on job satisfaction and keep the employee loyal with their job. Job satisfaction is the extent to which an employee is satisfied with the job and he/she employed for.

Hypothesis 1: There is a positive relationship between intrinsic reward and job satisfaction.

Hypothesis 2: Extrinsic rewards are positively related to job satisfaction.

\subsection{Intrinsic, Extrinsic Rewards and Organizational Commitment}

Intrinsic rewards are those which are non-cash rewards or not having any physical existence. For example, employee recognition, acknowledgement, professional growth, authority to immediate tasks, respect and appreciation are intrinsic rewards. On other side, extrinsic rewards are those which have physical existence and cash based rewards are lie under the category of extrinsic rewards. Examples office pay, salary, bonuses and such indirect forms of payment as flexibility in time. According to [8], commitment is a belief and perception of employee about the receiving of organizational values and goals as their own goals and values, employees shows acceptance to organizational policies and values to keep themselves attach with organization. Extrinsic compensation includes wages, promotion at job, social climate of organization, and job security, bonuses, increments, and overtime payments also comes under the domain of extrinsic rewards [9].

[10] Also supported the organizational commitment positive relation with the organizational performance. He described that lack of committed employees could decrease the performance of organizational and make less productive outcomes. Commitment could be raised by different types of incentives. [11] defined the commitment as a relation with rewards system. He defined that the intrinsic rewards had the great importance to integrate the commitment in employees. Organization provided the opportunities to employees by their performance for the recognition and acknowledgement as rewards and in result the employee emotionally attached with organization due to being recognized. The intrinsic rewards and social rewards found more helpful for employers to develop and construct the emotional attachment among employees towards organization goals and objectives [12]. According to [13], the supportive nature of employers has more committed employees because of social recognition given to them. [14] stated that when management were connected to employees in well-organized manner and paid them recognition and acknowledgement in return of their effective performance the employees are found more emotionally integrated in work and released more trust towards their job and remain loyal to organization. Employee's attitude was found positively related to organization perception support.

Hypothesis 3: There is a positive relationship between intrinsic reward and organization commitment. 


\section{Hypothesis 4: Extrinsic reward will positively predict the organizational commitment.}

\subsection{Relationship of Intrinsic, Extrinsic Rewards and Employee Attitudes}

The evidence of previous researches provided significant effect of intrinsic and extrinsic rewards with the job satisfaction and organizational commitment. [15] also suggested that the extrinsic rewards provided to employees showed significant positive effect on the employee attitude because the job satisfaction factor found active in motivation of employees. In other study [13] also defined that the monetary rewards played a vital role for the increment in employee's effort towards the work. He also described, by addition of extrinsic rewards the marginal value of effort will be equal to marginal cost added. The extrinsic rewards count as compensated value, which added the extra effort in employee work and raise their perception towards the organizational commitment and job satisfaction. [16] also supported the idea of [17] that the employee's attitude was affected by the organizational support perception. The expectations of employees towards rewards must be similar to the organizational presented rewards to employees, otherwise the conflicted attitude could be found among employees and dissatisfaction shown in employees about their job.

\subsection{Relationship of Intrinsic, Extrinsic Rewards and Perceived Organization Support}

The member activation could increase by motivating them towards pro social acts on behalf of organization, which could be possible by creating positive perception among employees about the organizational support.The positive and significant relation founded between perception of employees and effective rewards system. Employee performance positively increased by the perception of value would be given by organization to them. These expectations of incentive reciprocity motivate the employees to work effetely and efficiently on the end of organization as their obligation. Organizational commitment increased by different factors, from which one is the perception of employees about the support given by organization to the employees. [18] also supported the concept of perceived organizational support and showed the great relation between the organizational support and rewards and organizational commitment of employees.

\subsection{Perceived Organizational Support and Job Satisfaction}

The term job satisfaction is employees believe of how much well-being at their job or work. It is a perception of employee that how much he is well treated at job or how much he is badly treated at job [19]. The job satisfaction is much effective source for organization if the employees are more satisfied they will work committed to organizations goal otherwise they leave their job and the turnover ratio of organization will increased automatically which is deficit for the base of organization. Organization must have to satisfy their employee in return for their own satisfaction. The employees who feel the organization value and appreciate their work are satisfied and attached to their work more committed and shows positive behavior towards work.

Hypothesis 5: Perceived organizational support mediates relationship between intrinsic rewards and job satisfaction.

Hypothesis 6: Perceived organizational support mediates the relationship between extrinsic rewards and job satisfaction.

\subsection{Perceived Organizational Support and Organizational Commitment}

Any organization focuses on employee commitment based on employees' perception about the support from the organization. This is the reason when employees feel they are recognized and acknowledged by the management they feel satisfied and committed to the organization interests. Organizational commitment showed the employees perception about the organization. The employees attachment to their job is due to result of organizational perception in employees mind. Perceived organizational support (POS) submit to "the degree to which the organization give importance to employees' assistance and cares about their welfare” [20]. Rewards are primarily considered inducements leading to employee's satisfaction with their jobs, organizational commitment [21]. Rewards increase the performance of individuals and organization and among these rewards the financial rewards are very influential and enhance the motivation of the employees [22].

Hypothesis7: Perceived organization support mediates the relationship between intrinsic rewards and organization commitment. 
Hypothesis 8: Perceived organization support mediates the relationship between extrinsic rewards and organization commitment.

On the bases of above literature and formulated hypothesis, the hypothetical framework for the study is as under:

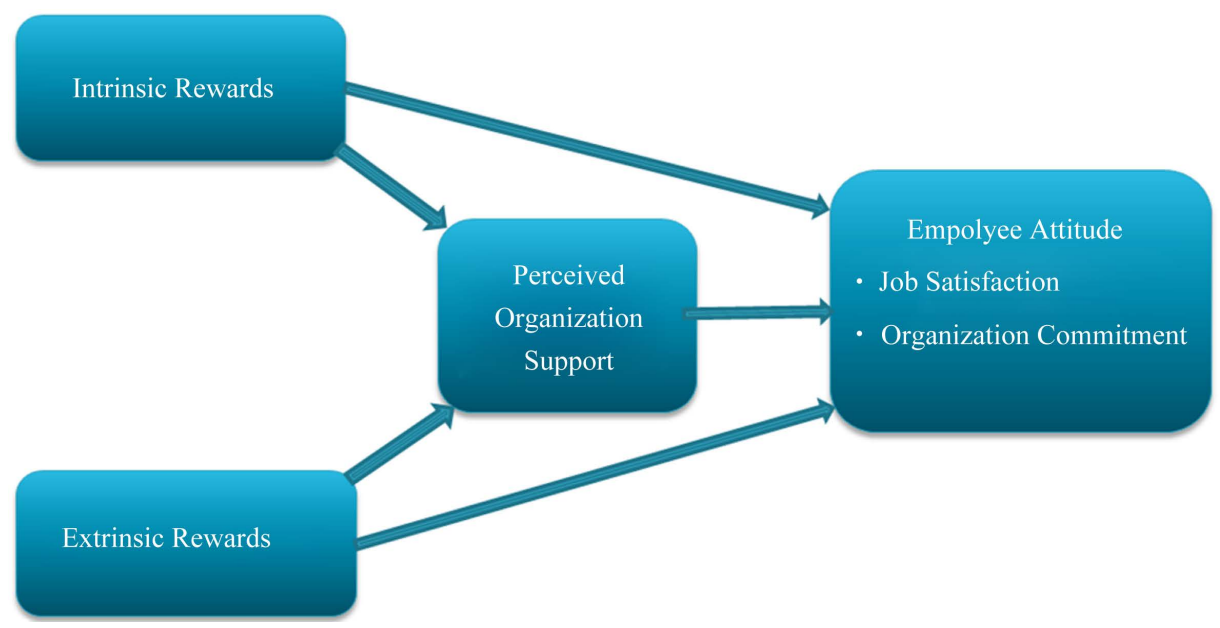

\section{Methodology}

\subsection{Study Design and Population}

The objective of this research work was to measure the consequences of incentives on employee attitudes and perception of organizational support. Perception of organizational support acted as mediating variable to effect the employee satisfaction and commitment level. A questionnaire based on 52 items covering intrinsic, extrinsic rewards, perceived organizational support, and subparts of employee attitude (job satisfaction and organization commitment) with creativity was checked with complete inspection. The Research was conducted in the city of Faisalabad. Targeted population was private and public institutions employees of Faisalabad. Employees were contacted for collection of their responses regarding job satisfaction, employee attitude and their perception about the organization. All level of management employees taken into account for the data collection including, teachers, industries employee, banking sector employees etc.

\subsection{Instrument}

Five-point (1 - 5) likert scale instrument (strongly agree to strongly disagree) was used. Negative/reverse coded questions were the part of questionnaire so that the employees could response with care. Following were the parts of questionnaire.

\subsection{Intrinsic Rewards}

Intrinsic rewards were measured by the questions taken from the study of Allen and Kilmann's (2001a). The tools based on the 7 items of intrinsic motivational rewards.

\subsection{Extrinsic Rewards}

Extrinsic rewards were also measured by the tool developed by Allen and Kilmann's (2001a). 6 items of this tool show the effects of motivational rewards to measure the effectiveness of extrinsic rewards.

\subsection{Job Satisfaction}

Job satisfaction has been taken as dependent variable in this study. 16 items tools are developed by Peter Warr, (1979) to measure the overall characteristics of employee's job satisfaction. 


\subsection{Organizational Commitment}

Organizational commitment questionnaire of Porter et al; (1974) was in this study to measure the commitment level of individuals.

\subsection{Perceived Organizational Support}

Perceived Organizational Support (POS) was measured by using Eisenberger et al., 1986, 1990.

\section{Results}

\subsection{Descriptive Statistics}

Table 1 shows the frequency distribution of gender wise respondents

\subsection{Correlation Analysis}

Table 2 shows Mean and Standard Deviation for the independent, dependent and mediating variables.

Independent variable intrinsic rewards mean is $(\bar{x}=3.56)$, which shows that the most of respondents remain in option, agrees and neutral about the IR allotted in organization. The standard deviation of intrinsic rewards is $(\sigma=0.68)$ which shows the deviation of results from the target. The other independent variable ER show the mean $(\bar{x}=3.61)$, which is higher than IR and standard deviation is $(\sigma=0.60)$ which is lower than IR. ER found more significant according to $(\bar{x}$ and $\sigma)$ from the target. Dependent variable the OC mean is $(\bar{x}=3.52)$ and deviation found from the point of target is $(\sigma=0.41)$. OC also shows less standard deviation errors in results. The second $Y_{2}$ variable JS result also found sufficient acceptable. Job satisfaction mean is $(\bar{x}=3.82)$, which is higher from all other variables of our study and its $(\sigma=0.52)$, found acceptable. The deviation error of mediator variable POS also shows acceptable results having a low figure of $(\sigma=0.58)$ and the mean value are $(\bar{x}=3.74)$. This table shows that the variables have low deviation from the standard target and acceptable figures. Having low " $\sigma$ " explains the lesser error in the respondents for the standard target.

\subsection{Regression Analysis}

Simple and multiple regression analysis along with hierarchal regression analysis was used test the impact of independent variables on dependent variable.

\section{Table 1. Gender wise respondents.}

\begin{tabular}{ccccc}
\hline & Gender & & \\
\hline & Frequency & Percent & Valid Percent & Cumulative Percent \\
\hline Male & 172 & 74.8 & 74.8 & 74.8 \\
Female & 58 & 25.2 & 25.2 & 100 \\
Total & 230 & 100 & 100 & \\
\hline
\end{tabular}

Table 2. Descriptive statistics and correlations.

\begin{tabular}{|c|c|c|c|c|c|c|c|c|}
\hline & & Mean & SD & 1 & 2 & 3 & 4 & 5 \\
\hline 1 & Intrinsic rewards & 3.5600 & 0.68 & 1 & & & & \\
\hline 2 & Extrinsic rewards & 3.6145 & 0.60 & $0.33^{* *}$ & 1 & & & \\
\hline 3 & Perceived organizational support & 3.5261 & 0.58 & -0.08 & $0.16^{*}$ & 1 & & \\
\hline 4 & Organizational support & 3.764 & 0.52 & $0.39 * *$ & $0.31^{* *}$ & $0.19^{* *}$ & 1 & \\
\hline 5 & Job satisfaction & 3.8236 & 0.41 & $0.40^{* *}$ & $0.54^{* *}$ & $0.34^{* *}$ & $0.23^{* *}$ & 1 \\
\hline
\end{tabular}

${ }^{* *}$ Correlation is significant at the 0.01 level (2-tailed); ${ }^{*}$ Correlation is significant at the 0.05 level (2-tailed). 
Table 3 reflects the coefficient and " $\tau$ " value understanding of IR and OC. First model of this table shows that " $\tau$ " value of IR is ( $\tau=6.45)$ which is less than its tabulated value and acceptable. $(6.45<2)$, so according to statistics rules " $\tau$ " value could be minimum 2 for acceptable. In model 2 , " $\tau$ " value of intrinsic rewards increase from $(\tau=6.45)$ to $(\tau=6.91)$ which shows the mediating effect increases the influences of IR on OC after adding mediating effect of POS. In second model $\beta$ of IR found to be $(\beta=0.25)$ which means by addition of one unit of IR the OC affected $25 \%$. POS beta is $(\beta=0.16)$ plus $(\beta=0.25)$ percent $\beta$ of IR shows that (40) percent variation in OC by adding one unit of " $\mathrm{X}$ " variable and one unit of mediating variable. The significance level of both models relies on $(0.00 \mathrm{P}=<0.001)$ statistically significant.

Table 4 demonstrates the study objective by showing the effects of mediator in this second design. The coefficient of ER is $(\beta=0.20)$ statically acceptable but decrease little bit from the first presentation but also the effectiveness of POS added $(\beta=0.10)$ in the results, cumulatively increase the coefficient level of first representation. The $\tau$ value of ER and POS is ( $\tau=4.57)$ and $(\tau=2.32)$ correspondingly. The $\tau$ value in second image also show the significant result and support that the ER has the great influence on employee perception about organization support and in results the organizational loyalty and attachment of employees also increases by adding every unit of independent variable.

Table 5 shows the $\tau$ value ( $\tau=7.83$ ) which is more than its tabulated value and significantly acceptable. The $\tau$ value of IR increases from $\tau=6.70 \%$ to $\tau=7.83 \%$. The $\tau$ value of POS also has significant result and found more than its calculated value as ( $\tau=6.78$ ). The IR shows more significant relation with employees JS to IR relation with OC. The $\beta$ value of IR also increases from first presentation of table, $(\beta=3.11)$ to $(\beta=3.33)$ percent. This table shows that mediating variables effecting the relation between " $\mathrm{X}$ " and "Y" variable.

Table 6 shows the ER and employee JS has acceptable correlation of $(\beta=0.47)$ more than OC and IR. The results demonstrate that ER has more significant impact on employee JS level compare to IR. The $\tau$ value also found significant at ( $\tau=9.72)$ more than its tabulated value and compare to IR value. The $(\beta=47)$ percent show with every component of ER inclusion the JS increase to (47\%) positively. The significance level in first presentation of table 9.4 is $(\mathrm{P}=<0.001)$ highly significant. The $\tau$ value in second image also show the significant

Table 3. Coefficient table of relationship of intrinsic rewards and organizational commitment.

\begin{tabular}{|c|c|c|c|c|c|c|}
\hline & \multirow{2}{*}{ Model } & \multicolumn{2}{|c|}{ Unstandardized Coefficients } & \multirow{2}{*}{$\begin{array}{c}\text { Standardized } \\
\text { Coefficients }\end{array}$} & \multirow{2}{*}{$\mathrm{t}$} & \multirow{2}{*}{ Sig. } \\
\hline & & $\beta$ & Std. Error & & & \\
\hline \multirow{2}{*}{1} & (Constant) & 2.69 & 0.13 & & 20.26 & 0.00 \\
\hline & IR & 0.24 & 0.04 & 0.39 & 6.45 & 0.00 \\
\hline \multirow{3}{*}{2} & (Constant) & 2.05 & 0.21 & & 9.68 & 0.00 \\
\hline & IR & 0.25 & 0.04 & 0.41 & 6.92 & 0.00 \\
\hline & POS & 0.16 & 0.04 & 0.23 & 3.81 & 0.00 \\
\hline
\end{tabular}

a. Dependent Variable: Organization Commitment.

Table 4. Coefficient table of relationship of extrinsic rewards and organizational commitment.

\begin{tabular}{|c|c|c|c|c|c|c|}
\hline & \multirow[t]{2}{*}{ Model } & \multicolumn{2}{|c|}{ Unstandardized Coefficients } & \multirow{2}{*}{$\begin{array}{c}\text { Standardized } \\
\text { Coefficients } \\
\text { Beta }\end{array}$} & \multirow[t]{2}{*}{$\mathrm{t}$} & \multirow[t]{2}{*}{ Sig. } \\
\hline & & $B$ & Std. Error & & & \\
\hline \multirow{2}{*}{1} & (Constant) & 2.76 & 0.16 & & 17.64 & 0 \\
\hline & ER & 0.21 & 0.04 & 0.31 & 4.97 & 0 \\
\hline \multirow{3}{*}{2} & (Constant) & 2.43 & 0.21 & & 11.54 & 0 \\
\hline & ER & 0.20 & 0.04 & 0.29 & 4.57 & 0 \\
\hline & POS & 0.10 & 0.05 & 0.15 & 2.32 & 0.02 \\
\hline
\end{tabular}

a. Dependent Variable: Organization Commitment. 
Table 5. Coefficient table of relationship of intrinsic rewards and job satisfaction.

\begin{tabular}{|c|c|c|c|c|c|c|}
\hline & \multirow{2}{*}{ Model } & \multicolumn{2}{|c|}{ Unstandardized Coefficients } & \multirow{2}{*}{$\begin{array}{c}\text { Standardized } \\
\text { Coefficients } \\
B\end{array}$} & \multirow[t]{2}{*}{$\mathrm{t}$} & \multirow{2}{*}{ Sig. } \\
\hline & & $B$ & Std. Error & & & \\
\hline \multirow{2}{*}{1} & (Constant) & 2.72 & 0.17 & & 16.15 & 0.00 \\
\hline & IR & 0.31 & 0.05 & 0.41 & 6.70 & 0.00 \\
\hline \multirow{3}{*}{2} & (Constant) & 1.36 & 0.25 & & 5.39 & 0.00 \\
\hline & IR & 0.33 & 0.04 & 0.44 & 7.84 & 0.00 \\
\hline & POS & 0.34 & 0.05 & 0.38 & 6.78 & 0.00 \\
\hline
\end{tabular}

a. Dependent Variable: Job Satisfaction

Table 6. Coefficient table of relationship of extrinsic rewards and job satisfaction.

\begin{tabular}{|c|c|c|c|c|c|c|}
\hline & \multirow{2}{*}{ Model } & \multicolumn{2}{|c|}{ Unstandardized Coefficients } & \multirow{2}{*}{$\begin{array}{c}\begin{array}{c}\text { Standardized } \\
\text { Coefficients }\end{array} \\
\text { Beta }\end{array}$} & \multirow[t]{2}{*}{$\mathrm{t}$} & \multirow{2}{*}{ Sig. } \\
\hline & & $B$ & Std. Error & & & \\
\hline \multirow{2}{*}{1} & (Constant) & 2.13 & 0.18 & & 12.04 & 0.00 \\
\hline & ER & 0.47 & 0.05 & 0.54 & 9.72 & 0.00 \\
\hline \multirow{3}{*}{2} & (Constant) & 1.38 & 0.23 & & 6.01 & 0.00 \\
\hline & ER & 0.43 & 0.05 & 0.50 & 9.26 & 0.00 \\
\hline & POS & 0.24 & 0.05 & 0.26 & 4.84 & 0.00 \\
\hline
\end{tabular}

a. Dependent Variable: Job Satisfaction

result and support that the ER has the great influence on employee perception about organization support and in results the organizational loyalty and attachment of employees also increases by adding every unit of " $\mathrm{X}$ " variable. In this table, second presentation by including the mediating variable POS also support our study hypotheses that when the ER system in any organization is well organized and constructive than the employee's perception increases along with the employee JS. The results show every unit of inclusion from POS n ER the employee satisfaction increases to $(\beta=66.7)$ percent, which is highly significant

\section{Discussion, Conclusion and Recommendations}

\subsection{Discussion}

The main objective of this study was to measure the significant relation of intrinsic and extrinsic rewards with employee job satisfaction and employee commitment. Job satisfaction and employee commitment refers to employee attitude. When the organization focuses on employee positive attitude the results will also found in positive manner. There are great evidences available in literature which defines the strong relationship between intrinsic, extrinsic rewards and employee job satisfaction and organizational commitment.

Behrman \& Perreault (1982) paying attention on employee attitude and their engagement in work and also emphasized the magnitude of intrinsic and extrinsic rewards in organizational accomplishment, organizations are comprised of range off assets, each sort of asset require importance and significant level of investment, while human capital is most important advantage in any organization among all competitive advantages.

\subsection{Conclusions}

The research results discussions conclude that employee's attitude plays vital role to raise the output of organizational motives. So, alternative hypotheses of our study, supported by great literature and results of our survey study also show significant output. We find that intrinsic and extrinsic rewards have much importance to satisfy employees and increase the employee retention level and job satisfaction level. When employees are satisfy with 
their job, they show great loyalty and commitment towards organization due to having perception of organizational support. Employee attitude varies on the base of employee perception about support from organization and employee's perception varies by the different type of motivational technique like intrinsic and extrinsic rewards.

This learning also supports to recognize the consequences of high satisfaction among employees and defines that employees would be more sincere towards the firm and how sincere efforts of employees affect the overall performance of the firms by time passing.

The conclusion of the study defines the importance of intrinsic and extrinsic rewards in raising the effort of employees in their work. This study is designed to describe the importance of employee job satisfaction and organizational commitment of employees. Intrinsic and extrinsic rewards show significant influence on the employee's perception to make significant boost in employee's satisfaction and motivation level. Intrinsic and extrinsic rewards are essential for employee satisfaction, if employees are rewarded appropriately with salaries, bonuses and increment for their hard work then they will be motivated greatly towards achievement of their representative objectives and in the same way if employees are acknowledged properly against their efforts then they will be more satisfied and happier towards their official objectives.

This research will help Pakistani organizations to develop plans about intrinsic, extrinsic rewards to enhance the employee positive attitudes and this study will draw attention to meaning of employee perception about organizational support and theoretical grounds of literature have proved that highly satisfied employees will work effectively and efficiently for organizations.

\subsection{Recommendations}

The main motive of any organization is to achieve the higher performance which could only be possible by employee's job satisfaction and organizational commitment. Management must keep the balance between the intrinsic and extrinsic rewards to get better output from employees.

The study provides some recommendations:

- Organizations should plan proper extrinsic and intrinsic rewards to their employees in Pakistani firms.

- Organizations must have to emphases on employee's satisfaction and commitment level.

- Excess of intrinsic or extrinsic rewards could also be harmful for the organization because these rewards can increase the fake needs of employees.

\subsection{Limitations and Suggestions for Future Research}

Time is firstly, the major issue or limitation for this study. In 4 to 5 month, it's very hard to get the responses in more huge quantity to measure the significant and more accurate results. Another limitation, the ratio of intrinsic and extrinsic rewards in true essence is found very low in Pakistani organizations. That's why fake responses by higher management are found common to save the image of their organization.

This study can be limited in nature because it's very hard to measure $100 \%$ perception of any employee. The perception is the mental state or mind set of employee, which could be calculated only by responses of employee or reading minds of employee.

Another aspect is limited by nature according to this study. Disclosure of transparent information from management is very much harder to obtain because often organizations do not want to disclose information related to rewards.

\section{References}

[1] Rhoades, L., Eisenberger, R. and Armeli, S. (2001) Affective Commitment to the Organization: The Contribution of Perceived Organizational Support. Journal of Applied Psychology, 86, 825-836. http://dx.doi.org/10.1037/0021-9010.86.5.825

[2] Allen, D.G., Shore, L.M. and Griffeth, R.W. (2003) The Role of Perceived Organizational Support and Supportive Human Resource Practices in the Turnover Process. Journal of Management, 29, 99-118. http://dx.doi.org/10.1177/014920630302900107

[3] Zare, E. (2012) Effect Perceived Organizational Support on Employees’ Attitudes toward Work. Science Series Data Report, 4, 28-34.

[4] Eisenberger, R., Huntington, R., Hutchison, S. and Sowa, D. (1986) Perceived Organizational Support. Journal of Ap- 
plied Psychology, 71, 500-507. http://dx.doi.org/10.1037/0021-9010.71.3.500

[5] Schuler, R.S. and Jackson, S.E. (1996) Human Resource Management: Positioning for the 21st Century. 6th Edition, West Publishing Company, New York.

[6] Dewhurst, M. (2010) Motivating People: Getting Beyond Money. Business Source Complete, Ipswich.

[7] Howard, L.W. and Dougherty, T.W. (2004) Alternative Reward Strategies and Employee Reactions. Compensation \& Benefits Review, 36, 41-51. http://dx.doi.org/10.1177/0886368703261273

[8] Porter, L.W., Steers, R.M., Mowday, R.T. and Boulian, P.V. (1974) Organizational Commitment, Job Satisfaction, and Turnover among Psychiatric Technicians. Journal of Applied Psychology, 59, 603-609. http://dx.doi.org/10.1037/h0037335

[9] Mahaney, R.C. and Lederer, A.L. (2006) The Effect of Intrinsic and Extrinsic Rewards for Developers on Information Systems Project Success. Project Management Journal, 37, 42-54

[10] Cohen, A. (1993) Organizational Commitment and Turnover: A Meta-Analysis. Academy of Management Journal, 36, 1140-1157. http://dx.doi.org/10.2307/256650

[11] Deci, E.L. (1971) Effects of Externally Mediated Rewards on Intrinsic Motivation. Journal of Personality and Social Psychology, 18, 105-115. http://dx.doi.org/10.1037/h0030644

[12] Burke, W.W. (2002) Organizational Change: Theory and Practice. Sage, Thousand Oaks.

[13] Adeyemo, D.A. and Aremu, A.O. (1999) Career Commitment among Secondary School Teachers in Oyo State, Nigeria: The Role of Biographical Mediators. Nigerian Journal of Applied Psychology, 5, 184-194.

[14] Lazear, E.P. (1986) Salaries and Piece Rates. Journal of Business, 59, 405-431. http://dx.doi.org/10.1086/296345

[15] Lazear, E.P. (2000) Performance Pay and Productivity. The American Economic Review, 90, 1346-1361. http://dx.doi.org/10.1257/aer.90.5.1346

[16] Magione, T. and Quinn, R. (1975) Job Satisfaction, Counterproductive Behavior and Drug Uses at Work. Journal of Applied Psychology, 60, 114-116. http://dx.doi.org/10.1037/h0076355

[17] Probst, M.T. and Brubaker, T.L. (2001) The Effects of Job Insecurity on Employee Outcome: Cross-Sectional and Longitudinal Exploration. Journal of Occupational Health Psychology, 6, 139-159. http://dx.doi.org/10.1037/1076-8998.6.2.139

[18] Allen, N. and Meyer, J. (1996) Affective, Continuance and Normative Commitment to the Organization: An Examination of Construct Validity. Journal of Vocational Behavior, 49, 252-276. http://dx.doi.org/10.1006/jvbe.1996.0043

[19] Locke, E.A. (1976) The Nature and Causes of Job Satisfaction. In: Dunnette, M.P., Ed., Handbook of Industrial and Organizational Psychology, Rand McNally, Chicago, 1297-1350.

[20] Eisenberger, R., Huntington, R., Hutchison, S. and Sowa, D. (1986) Perceived Organizational Support. Journal of Applied Psychology, 71, 500-507. http://dx.doi.org/10.1037/0021-9010.71.3.500

[21] Lawler, E. and Douglas, H. (1970) Relationship of Job Characteristics to Job Involvement, Satisfaction, and Intrinsic Motivation. Journal of Applied Psychology, 54, 305-312. http://dx.doi.org/10.1037/h0029692

[22] Rewards Increase the Performance of Individuals and Organization and among These Rewards the Financial Rewards Are Very Influential and Enhance the Motivation of the Employees (Ojokukuand Sajuyigbe, 2009). 